\title{
A FELICIDADE EM FOCO - MENSURANDO CONCEITO METAFÍSICO PARA ESTRATÉGIA GOVERNAMENTAL E RECOMENDAÇÕES ORGANIZACIONAIS
}

\author{
HAPPINESS IN FOCUS - MEASURING METAPHYSICAL CONCEPT \\ FOR COUNTRY STRATEGY AND ORGANIZATIONAL \\ RECOMMENDATIONS
}

\author{
Marcos Bacellar de Carvalho ${ }^{1}$, Carlos Alberto Gonçalves ${ }^{2}$ \\ e Daniel Jardim Pardini ${ }^{3}$
}

\begin{abstract}
Resumo
Para Aristóteles, a Felicidade seria a razão última da vida. Pesquisadores demonstraram que ela está positivamente correlacionada com a criatividade e produtividade. Portanto, o tema possui relevância para os indivíduos e as organizações. O Princípio da Utilidade de Bentham (1789) propunha que cada ação dos indivíduos deveria ser julgada pela sua contribuição final à Felicidade, positiva ou negativa. Daí a questão deste estudo: conceitos organizacionais (ex: Inovação, Competitividade, Sustentabilidade, Qualidade de Vida), tão frequentes na literatura técnica sobre administração nas últimas duas décadas, são "úteis" para a Felicidade? E, consequentemente, para os indivíduos e para as próprias organizações? Este trabalho propõe um modelo de relacionamento desses conceitos, cuja análise respondeu afirmativamente a essa questão. A proposta de Hume (1741) e Bentham, para que administradores públicos considerem a Felicidade como referência ao estabelecerem sua estratégia de governo seria, então, muito atual.

Palavras-chave: Mensuração da Felicidade; Qualidade de Vida; Competitividade; Sustentabilidade; Inovação; Desempenho Social e Econômico.
\end{abstract}

Faculdade de Ciências Empresariais (FUMEC). E-mail: bacellar@ecmsa.com.br

Universidade FUMEC. E-mail: carlos@face.ufmg.br

E-mail: pardinidaniel@hotmail.com 


\begin{abstract}
For Aristotle, Happiness should be ultimate reason for life. Researchers have demonstrated that Happiness is positively correlated with creativity and productivity. So, the subject is relevant for each one as well as for organizations. Bentham's Utility Principle proposed that each people action should be judged according its final contribution to Happiness, whether positive or negative. Now the question of this work arises: are the organizational concepts (e.g.: Innovation, Competitiveness, Sustainability, Quality of Life), so frequent in administration technical literature, "useful" for Happiness? Are they "useful" for people as well as for organizations? The analysis of an interrelationship model proposed, covering such concepts, has positively answered this question. Hume (1741) and Bentham's proposal, in which administrators should take Happiness in account when establishing their government strategy, is very actual.

Keywords: Measurement of Happiness; Quality of life; Competitiveness; Sustainability; Innovation; Social and economic performance.
\end{abstract}

\title{
1 Introdução
}

\subsection{Felicidade na Grécia Antiga e Bentham com o Utilitarismo}

Na Grécia Antiga, Aristóteles de Estagira (384 a.C. a 322 a.C.) já considerava que o bem supremo da vida é a felicidade e que a inteligência, a ética, o prazer e os bens materiais são apenas meios para se chegar a ela.

Da Grécia Antiga vêm ainda dois conceitos associados à felicidade (FAEME, 2009; FERNANDES, 2005): o estoicismo e o hedonismo. O estoicismo parte do princípio de que o universo seria de natureza racional, o homem para com ele manter equilíbrio, deveria ser também racional, sem espaço para as paixões, angústias, alegrias, dissabores e sofrimentos espirituais; as glórias e as perdas da vida devem ser suportadas serenamente para não se perturbar a alma. A felicidade seria alcançada pela virtude estoica. O segundo conceito, o hedonismo, propunha que o bem é tudo aquilo que traz prazer imediato. Epicuro de Samos (341-270 a.C.) aprimorou o conceito de hedonismo ao dizer que o bem não era o que conduzia a qualquer prazer, mas a prazeres "calmos", ao invés dos intensos, violentos.

Depois da contribuição dos filósofos gregos, ao longo dos séculos seguintes, o conceito de Felicidade continuou a ser elaborado, explicitado e discutido por filósofos, cientistas sociais ou não, líderes espirituais e de governo, escritores e artistas das mais variadas especialidades. Embora inúmeras manifestações sobre o tema tenham ocorrido, elas eram ainda o resultado de reflexões filosóficas ou poéticas, não havendo registro de um tratamento mais elaborado, até a publicação, em 1789, do livro de Jeremy Bentham, intitulado "Uma introdução aos Princípios da Moral e da Legislação". A ideia central era a de que o bem-estar das pessoas seria o resultado do balanço (a soma) dos prazeres e das dores (sofrimentos) por elas experimentados ao longo de suas vidas.

Bentham (1979) formulou o Princípio da Utilidade. O balanço deveria ser feito para tudo o que afeta o ser humano no aspecto físico, mental e espiritual. Desse modo, embora, na época, não houvesse ainda uma definição de bem-estar subjetivo (BES), como hoje é aceito pelos psicólogos, era isso que Bentham já propunha naquela época, quando dizia "soma dos prazeres e dores". Sua filosofia foi chamada de "Utilitarismo" porque propunha que as ações

Rev. Adm. UFSM, Santa Maria, v. 3, n. 2, p. 269-287, mai./ago. 2010 
deveriam ser avaliadas pela sua utilidade (BRICH, 2005) em contribuir para "um maior bemestar ao maior número possível de pessoas" (BENTHAM, 1979), de modo inverso quanto mais inútil à felicidade, pelo fato do balanço resultar negativo, maior deveria ser a punição ou pena. Veenhoven (2007) comenta que, ao invés de "Utilitarismo", tal filosofia deveria ter sido chamada de happyism, uma vez que propõe que as ações sejam avaliadas pelas suas consequências sobre a felicidade.

O Utilitarismo partia do entendimento de que o bem-estar subjetivo (embora não tenha sido usada essa expressão na época) seria o objetivo permanente e maior dos indivíduos, e que a sociedade deveria atuar por meio de uma legislação que favorecesse sua obtenção. Bentham retoma, então, o conceito de hedonismo.

Depois de Bentham e de seus seguidores houve um hiato no que se refere ao tratamento mais elaborado sobre o conceito de Felicidade. Estudos sobre o assunto só foram retomados apenas no século XXI, quando psicólogos acadêmicos passaram a estudar o assunto.

Se, conforme Hume (1980), "o objetivo fundamental de todo o esforço humano é alcançar a felicidade" é surpreendente que, somente muito recentemente, o assunto tenha merecido maior atenção por parte dos pesquisadores. Mesmo os psicólogos, para os quais o tema poderia estar mais imediatamente relacionado e que poderiam ter maior interesse em investigar as causas que levam as pessoas a se sentirem felizes, priorizaram o estudo das causas do sofrimento humano, da infelicidade, tais como a depressão, a angústia e o estresse (GIACOMONI, 2004). Após os psicólogos, vieram os sociólogos e os economistas, afinal, o tema felicidade é também do interesse dessas ciências sociais. Contudo, em Administração, o assunto segue em estado latente.

\subsection{Felicidade e a ciência da administração}

Sendo a felicidade a razão maior da vida, existe lógica no fato de os governos terem como prioridade desenvolver, implementar e melhorar as condições que a favoreçam. Em linha com essa abordagem está Meirelles (1995) ao considerar que a finalidade da administração pública é o bem comum da coletividade e que toda atividade do administrador público deve ser orientada neste sentido, mais ainda, que a Administração foi criada pela sociedade como um meio para atingir o bem-estar social.

Desde a década de 1970, o governo do país de um "pequeno reino", nas encostas do Himalaia (chamado Butão), considera formalmente que o maior objetivo do governo é a felicidade do povo, criando a expressão "Felicidade Interna Bruta" (FIB). Seria, então, o FIB, e não mais o PIB, o guia para o desenvolvimento do seu país. Desse modo, as políticas públicas e a legislação foram estabelecidas como suporte a esse propósito de governo. Esta inédita abordagem, de administrar um país em função de indicadores relacionados à felicidade do povo, despertou interesse internacional, levando outros, como as Filipinas, a também adotar o FIB como referência, do mesmo modo que governos de países da OECD, como a França e o Reino Unido demonstraram também interesse no assunto (SEAGER; STEWART, 2010).

Enquanto os modelos tradicionais de desenvolvimento têm como objetivo primordial o crescimento econômico, o conceito de FIB se sustenta sobre quatro pilares: a promoção de um desenvolvimento socioeconômico sustentável e igualitário; a preservação e a promoção dos valores culturais; a conservação do meio-ambiente natural e o estabelecimento de uma boa governança. Em uma pesquisa internacional sobre felicidade média de diferentes nações, (SCIENCE DAILY, 2006), o país Butão aparece em oitavo lugar entre 178 países, situação bastante favorável quando se correlaciona esse índice à sua renda per capita, ainda muito baixa, cerca 
de US\$2000. Seria este resultado surpreendente uma consequência da administração pelo FIB ao invés do PIB?

Aos administradores nas empresas e às demais organizações interessa ter pessoas mais felizes porque elas são mais produtivas (OSWALD; PROTO; SGROI, 2009), mais criativas (CSIKSZENTMIHALYI, 1997; AMABILE, 2005) e mais fáceis de lidar (GIACOMONI, 2004).

\subsection{Conceitos organizacionais recentes em administração}

De duas décadas para cá, há uma série de novos conceitos, tais como Inovação, Competitividade, Sustentabilidade, Qualidade de Vida e ainda Gestão do Conhecimento, este último que tem na infraestrutura para Tecnologia de Informação e Comunicação uma importante antecedente para disseminação das informações necessárias para que esses conceitos sejam implementados e desenvolvidos. Complexos e abrangentes, tais conceitos afetam o indivíduo, as relações entre os indivíduos, as relações entre estes com o meio ambiente, com a cultura das sociedades em que vivem e com as instituições. Se as implicações na vida das pessoas são tão relevantes e eles vêm sendo tão frequentes e intensamente mencionados no meio acadêmico, empresarial, governamental e ainda pela mídia, como importantes e benéficos para as organizações, seja uma simples empresa, seja uma nação, tais conceitos não podem ser um obstáculo na busca da felicidade, "a razão suprema da vida", conforme Aristóteles de Estagira (2002). Ao contrário, eles devem favorecer a felicidade dos indivíduos e, de modo coletivo, da população como um todo. Carvalho (2010) identificou diversos estudos, realizados por diferentes pesquisadores, sobre relações entre conceitos como felicidade, inovação, competitividade, desempenho econômico, sustentabilidade, qualidade de vida. Contudo, estes estudos normalmente envolveram dois, no máximo três conceitos. O objetivo deste trabalho é analisar a relação de um conjunto maior de construtos com a felicidade do mesmo modo como eles se interrelacionam, em um modelo lógico de causa e efeito.

\section{Revisão da literatura}

\subsection{O conceito de felicidade e as avaliações quantitativas realizadas}

Neste trabalho, o conceito de felicidade é equivalente ao de "bem-estar subjetivo" (BES), como chamado, na Psicologia Positiva, o ramo desta ciência social que visa a entender o que faz as pessoas se sentirem felizes. Diener e Lucas (2000) entendem o BES como um construto que somente pode ser mensurado por autoavaliação do indivíduo, pelo fato de envolver aspectos que só podem ser avaliados pelo próprio respondente; indicadores externos ao indivíduo, por mais apropriados que pareçam à primeira vista, são incapazes de realizar tal medição. É o indivíduo, com sua personalidade, sua experiência de vida, seus valores em equilíbrio com a cultura da sociedade em que vive quem irá ponderar tais variáveis ao fazer uma apreciação global de sua vida.

O BES é composto por duas dimensões: uma emocional e outra cognitiva. A dimensão emocional fornece o resultado de uma avaliação entre as emoções positivas e negativas experimentadas pelo indivíduo. A dimensão cognitiva envolve o julgamento sobre a satisfação em relação à vida de um modo geral. Essa dimensão, apesar de cognitiva, é ainda subjetiva, pois cabe somente ao indivíduo determinar quais são os aspectos que considera em sua avaliação e qual a importância de cada um deles, ou seja, a ponderação de cada um. 
Veenhoven (2008) complementa dizendo que felicidade é um estado subjetivo da mente, que ele define como a avaliação global que uma pessoa faz de sua vida como um todo. Reforça o caráter subjetivo, mas acrescenta que ela cobre todos os domínios da vida, não somente alguns deles (ex: satisfação com a vida no trabalho, no casamento etc.) e que resulta da experiência acumulada de vida, e não de um curto período de tempo apenas.

Veenhoven (2009), da Universidade de Erasmus na Holanda, mantém um banco de dados, disponibilizado ao público na Internet, onde estão dados de diversas pesquisas feitas por diferentes pesquisadores em diversos países, ao longo de muitos anos, cobrindo grande número de nações. O próprio Veenhoven (2009) agrupou os resultados de boa parte dessas pesquisas sobre Felicidade, realizadas no período de 2000 a 2008, empregando metodologia descrita no capítulo sete "How Data are Homogenized" de seu e-book. Os dados que resultaram deste trabalho de consolidação referente à Felicidade média dos indivíduos de 144 nações foram usados no presente estudo.

A partir da década de 1970, a construção do conhecimento sobre a felicidade pela psicologia positiva levou a um conjunto de teorias citadas por Carvalho (2010), entre elas: a teoria da força do feedback negativo de Gottman (1994) que demonstrou que, para haver percepção positiva, o número de eventos positivos deve ser de cinco a seis vezes maior que o de eventos negativos; a teoria da adaptação às circunstâncias de Brickman e Campbell (1971) que demonstrou haver tendência à volta a um ponto de equilíbrio depois de decorrido algum tempo entre um evento positivo ou negativo; a teoria da influência da cultura de Kitayama e Markus (2000), entre outros, que demonstraram que certas características (ex: autoestima e orgulho) são vistas como positivas em algumas culturas e negativas em outras; e a teoria das relações sociais de Bradburn (1969), que demonstrou a importância das relações sociais na felicidade. Diener e Oishi (2005) demonstraram que as relações sociais são mais relevantes que a prosperidade material, por essa razão eles disseram que é um erro colocar o dinheiro acima delas.

\subsection{Conceitos organizacionais}

Embora a análise crítica da literatura a respeito de cada um desses conceitos não tenha sido o objetivo de seu trabalho, Carvalho (2010) descreve-os citando definições de diferentes autores e a polêmica resultante quando não há consenso a respeito. Aqui será descrito o significado de cada um deles de modo bastante resumido.

Tecnologia de Informação e Comunicação (TIC): trata-se de uma variável antecedente da Gestão de Conhecimento (GC), cuja relevância na obtenção de altos desempenhos de diferentes processos tem sido ressaltada por diversos autores, entre eles, Drucker (1999) e Davemport e Prusak (1998). É um meio ou material necessário para extrair e construir o conhecimento. Para Machlup (1984 apud SANTOS et al., 2001), a informação seria a matéria-prima para a geração de conhecimento. Drucker (1999, p. 32) diz que informação "são dados dotados de relevância e propósito". Gonçalves (2006) ressalta que as tecnologias de informação e comunicação trouxeram novos modos de criação, coleta, armazenamento, combinação e utilização do conhecimento. Por essa razão, TIC é empregada como proxy da GC.

Inovação: alguns autores, como Schumpeter (1983), consideram que inovação só se aplica a algo novo, um novo produto, um novo processo, um novo mercado, novo método de gestão etc. Já Mitelka (2000) considera que melhoria incremental é também inovação. Outro ponto de polêmica está relacionado aos indicadores para inovação, se eles devem medir tão somente resultados (outputs) ou se também medir as condições que favorecem, que facilitam, a inovação (inputs). 
Competitividade: Tyson (1992) considera que competitividade está associada ao crescimento sustentável do padrão de vida dos cidadãos de um país, sendo este adequadamente competitivo nos mercados globais. Garelli (2006) propôs duas definições, uma com enfoque acadêmico e outra com enfoque empresarial:

- acadêmica: competitividade de nações é o campo do conhecimento econômico que analisa os fatos e as políticas que determinam a capacidade de uma nação de criar e de manter um ambiente que sustente maior criação de valor para suas empresas e mais prosperidade para seu povo;

- empresarial: competitividade de nações que visa identificar como as nações criam e mantêm um ambiente que sustente a competitividade de suas empresas.

Apesar das críticas de Porter (1999), Krugmam (1994) e Thompson (2002), este último citando mais dezessete autores, sobre a inadequação da aplicação do conceito competitividade para nações, ainda assim ela vem sendo avaliada quantitativamente por diferentes organizações.

Desempenho econômico: indicadores econômicos, como renda per capita ou PIB, não foram criados para medir o bem-estar das populações, contudo talvez a convicção que viabilizam acesso a bens e serviços (ex.: boa educação, planos de saúde, bens materiais que trazem conforto), que propiciam maior padrão de vida, explique a razão do bombardeio diário da mídia com indicadores econômicos. O conceito de padrão de vida é menos complexo e abrangente, está relacionado à renda do indivíduo. Assim, uma pessoa com alto padrão de vida consome produtos e serviços de preços mais elevados, como exemplo: casas ou apartamentos, hotéis, restaurantes, vinhos, roupas, automóveis etc. De fato indicadores de renda, tais como PIB ou renda per capita são mais familiares ao público que o mais famoso índice de qualidade de vida - o de Desenvolvimento Humano (IDH). De acordo com Oswald (1997), as pessoas não têm interesse genuíno em indicadores de Desempenho Econômico, pois eles resultam da crença disseminada de que estão associados ao padrão de vida, este que seria um antecedente, uma pré-condição para a Felicidade. A inadequação de tão intenso foco em renda como variável única antecedente da Felicidade já era comentada por Celso Furtado (1974, p. 116), que, em seu livro "O Mito do Desenvolvimento" dizia:

Por que ignorar, na medição do PIB, o custo para a coletividade da destruição dos recursos naturais não-renováveis, e o dos solos e florestas (dificilmente renováveis)? Por que ignorar, no PIB, a poluição das águas e a destruição total dos peixes nos rios em que as usinas despejam seus resíduos?

Desempenho ambiental: refere-se à qualidade atual do meio-ambiente, ou seja, qualidade do ar, das águas, do solo, da biodiversidade, entre outros.

Sustentabilidade: trata-se de um conceito cuja construção demorou quarenta anos. Em seu trabalho, Carvalho (2010) fez um resumo dos principais eventos que levaram ao entendimento atual desse conceito, o qual tem sua mais famosa definição a do relatório da Comissão Bruntland (UNITED NATIONS, 1987, p. 1):

\footnotetext{
O desenvolvimento que procura satisfazer as necessidades da geração atual, sem comprometer a capacidade das gerações futuras de satisfazerem as suas próprias necessidades. Ele contém dois conceitos-chave:

- O conceito de necessidades, em particular as necessidades essenciais dos mais pobres no mundo, para os quais deve ser dada máxima prioridade;

- A idéia das limitações impostas pelo estado da tecnologia e da organização social sobre a capacidade do meio-ambiente atender às necessidades atuais e futuras.
} 
Qualidade de Vida: o conceito adotado no estudo é equivalente ao significado de bem-estar, seja de um indivíduo, seja de uma população, podendo ser aplicado a uma região ou a uma nação. O conceito de bem-estar ou de Qualidade de Vida envolve uma série de aspectos, tais como: lazer, segurança, vida social, saúde física e mental, qualidade ambiental, educação, adaptação à cultura do local, nível de renda entre outros. Qualidade de vida pode ser entendida de dois modos distintos: primeiramente com base em sua definição, que a define como objetiva e externa ao indivíduo, podendo ser avaliada por meio de um conjunto de indicadores, cada um deles relacionados aos diferentes aspectos que fazem parte do conceito. Muitas vezes, para se medir apenas um dos aspectos, é empregada uma coleção de indicadores, de modo que se tenha uma cadeia até se obter o índice agregado. O segundo entendimento de qualidade de vida está relacionado à avaliação subjetiva que as pessoas fazem de suas vidas, só possível de ser "medida" por autorrelato, ou seja, pelo depoimento da própria pessoa, que, ao fazer isso, emprega componentes cognitivo e afetivo em sua avaliação. Esse segundo entendimento de qualidade de vida assume o conceito de Felicidade. Neste trabalho, Qualidade de Vida tem o primeiro significado, ou seja, é aquela que pode ser avaliada, medida de modo objetivo e externo ao indivíduo; por essa razão é normativa. Pela sua própria razão de ser, a Qualidade de Vida normativa, embora diferente do conceito de Felicidade, deve guardar uma relação forte e positiva com esta última, afinal, conforme Constanza et al. (2008), os indicadores objetivos seriam variáveis proxy de experiências subjetivas daqueles que os definiram. Do mesmo modo, uma vez que na Qualidade de Vida estão incluídas a qualidade ambiental e a renda, todos os demais construtos considerados neste estudo (exceção de "Felicidade") são considerados como antecedentes dela (Qualidade de Vida).

\section{3 Índices agregados para representar os construtos e o modelo proposto}

Os conceitos organizacionais, tais como os de Inovação, Competitividade, Sustentabilidade e Qualidade de Vida, são bastante complexos, de modo que, para representálos, a solução encontrada por diferentes organizações foi o desenvolvimento de índices agregados, compostos, cada um, por uma cadeia de indicadores relacionados a diferentes aspectos contidos no respectivo conceito.

As medições referentes a cada um dos índices escolhidos, disponíveis ao público, resultam de uma mistura de dados objetivos e de percepções (quantificadas também), obtidas em entrevistas realizadas em pesquisas de opinião cuidadosamente planejadas. Os resultados obtidos nessas medições, realizadas por organizações internacionalmente reconhecidas, foram por elas analisados quanto à sua validade estatística, incluindo atendimento a critérios pré-definidos quanto missing values. A utilização de dados secundários de qualidade disponíveis ao público foi importante recurso usado; contudo, isso, obviamente, impõe uma limitação à pesquisa e ao modelo proposto, ou seja, a necessidade de haver medições para um grande conjunto de nações para o construto considerado.

Carvalho (2010) identificou, com frequência, mais de um índice para cada construto, levando à necessidade de selecionar, entre eles, qual iria representá-los. Os critérios de seleção adotados foram: maior cobertura do conceito pelos aspectos considerados nos índices agregados bem como maior número de países na survey realizada pela respectiva organização que a conduziu. O quadro 1 apresenta os índices selecionados para representar cada conceito. 


\begin{tabular}{|l|l|l|l|}
\hline Indicador & \multicolumn{1}{|c|}{ Fonte } & Índice & Escala \\
\hline Felicidade & World Database of Happiness & Happiness & $0-10$ \\
\hline Competitividade & $\begin{array}{l}\text { World Econo mic Forum C } \\
2008\end{array}$ & $\begin{array}{l}\text { Global Competitiveness } \\
\text { Index 2008 }\end{array}$ & $1-7$ \\
\hline Inovação & $\begin{array}{l}\text { The Global Innovation } \\
\text { Rankings and Report 2009 }\end{array}$ & $\begin{array}{l}\text { Global Innovation Index } \\
\text { (Gll) 2009 }\end{array}$ & $1-7$ \\
\hline $\begin{array}{l}\text { Prontidão e uso de } \\
\text { Tecnologia da } \\
\text { Informação }\end{array}$ & $\begin{array}{l}\text { The Global Information } \\
\text { Technology Report 2009 } \\
\text { (INSEAD) }\end{array}$ & $\begin{array}{l}\text { Networked Readiness } \\
\text { Index (NRI) 2009 }\end{array}$ & $1-7$ \\
\hline $\begin{array}{l}\text { Qualidade de Vida } \\
\text { Unit's quality-of-life index }\end{array}$ & $\begin{array}{l}\text { The Economist Intelligence } \\
\text { Unit's quality-of-life index }\end{array}$ & Quality-of-life index & 1 a 10 \\
\hline $\begin{array}{l}\text { Desempenho } \\
\text { Econômico }\end{array}$ & $\begin{array}{l}\text { Environmental performance } \\
\text { index - 2008 }\end{array}$ & $\begin{array}{l}\text { Environmental } \\
\text { Performance Index }\end{array}$ & US $\$ 100$ \\
\hline $\begin{array}{l}\text { Desempenho } \\
\text { Ambiental }\end{array}$ & $\begin{array}{l}\text { Sustainable Society } \\
\text { Foundation 2008 }\end{array}$ & $\begin{array}{l}\text { Sustainable Society } \\
\text { Index (SSI) }\end{array}$ & $0-10$ \\
\hline Sustentabilidade &
\end{tabular}

Quadro 1 - Índices selecionados para representar os construtos

Fonte: Carvalho (2010).

*Nota: PPP do inglês, Power Purchasing Parity, trata-se de um índice para assegurar o mesmo poder de compra quando se faz comparações do PIB entre nações, sendo introduzido um fator de correção referente à taxa de inflação interna e à taxa cambial da moeda do respectivo país em relação ao dólar americano.

Selecionados os índices agregados para representar cada construto, foi possível, em função da estrutura de cada um, propor o modelo lógico de relacionamento desses construtos com a Felicidade, apresentado na figura 1, o qual encontra fundamentação no referencial teórico apresentado por Carvalho (2010). No modelo, alguns construtos não apresentam relação direta com a Felicidade; contudo afetam-na indiretamente, via outros construtos. Como exemplo, a Inovação, a Competitividade (CANTWELL, 2002) e o Desempenho Econômico (DE).

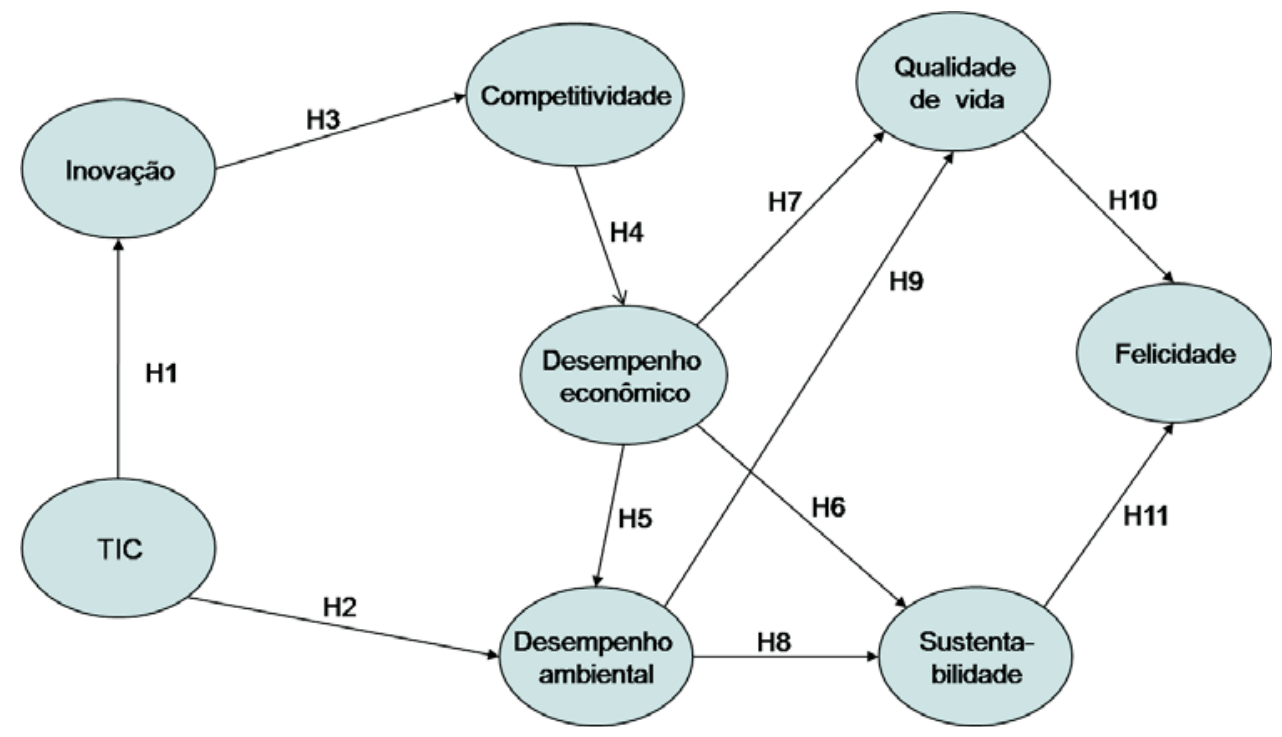

Figura 1 - Proposta de modelo explicativo para a Felicidade Fonte: Carvalho (2010) 
Nota: Nos modelos de rede nomológica, construtos são representados por elipses, enquanto variáveis objetivas, tais como indicadores numéricos, são ilustradas por meio de retângulos. No caso presente, os índices escolhidos, mesmo que numéricos, representam quantitativamente um conjunto de variáveis abstratas contidas em um mesmo conceito complexo; tais variáveis foram escolhidas como proxy, por essa razão são, ainda assim, consideradas como construtos e representadas por elipses no modelo.

O mesmo ocorre com o Desempenho Econômico e com a Felicidade, pois a tão discutida relação "dinheiro X Felicidade" não é direta, pois é intermediada pelas "coisas" que o dinheiro viabiliza, inseridas nos indicadores objetivos do construto Qualidade de Vida. A influência dos construtos não relacionados diretamente com a Felicidade no modelo pode ser calculada pela multiplicação dos coeficientes de determinação. Essa proposta de modelo com menos relações ajuda a evitar problemas de multicolinearidade na análise estatística. As seguintes hipóteses são apresentadas:

- h1: Prontidão e Uso de Tecnologia de Informação e Comunicação explica positivamente e de forma significativa (eps) a Inovação;

- h2: Prontidão e Uso de Tecnologia de Informação e Comunicação (eps) o Desempenho Ambiental;

- h3: Inovação (eps) a Competitividade;

- h4: Competitividade (eps) o Desempenho Econômico;

- h5: Desempenho Econômico (eps) o Desempenho Ambiental;

- h6: Desempenho Econômico (eps) a Sustentabilidade (H6);

- h7: Desempenho Econômico (eps) a Qualidade de Vida;

- h8: Desempenho Ambiental (eps) a Sustentabilidade;

- h9: Desempenho Ambiental (eps) a Qualidade de Vida;

- h10: Qualidade de Vida (eps) a Felicidade;

- h11: Sustentabilidade (eps) a Felicidade.

\section{Metodologia e resultados das análises bivariadas}

A pesquisa, caracterizada como conclusiva descritiva e de corte transversal, utilizou dados secundários, obtidos de pesquisas realizadas pelas entidades identificadas no quadro 1. Em se tratando de dados secundários, cuidado especial foi tomado na verificação do controle da qualidade adotado pelas respectivas organizações que conduziram as surveys. Na sequência, procederam-se análises bivariadas e multivariada, com o auxílio dos softwares Microsoft Excel $2007^{\circledR}$, SmartPLS 2.0 e SPSS $16.0{ }^{\circledR}$. A análise bivariada consistiu de medidas de associação entre duas variáveis, tais como correlação e regressão.

Além da correlação de cada construto com a Felicidade cujos coeficientes de Pearson são apresentados na primeira coluna da tabela 1, no intuito de melhor explorar os dados, foram também verificadas todas as possíveis relações entre os construtos em análise. Todos os coeficientes de correlação de Pearson, não só com a Felicidade, como também entre todos os possíveis pares, mostraram-se intensos, significativos e positivos. Exceção apenas para as relações da Sustentabilidade, não com a Felicidade, como também para os demais construtos. 
Tabela 1 - Matriz de correlação entre as variáveis

\begin{tabular}{l|l|l|l|l|l|l|l|l}
\hline & Felic. & Comp. & Inov. & TIC & QV & $\begin{array}{l}\text { Desemp. } \\
\text { Econ. }\end{array}$ & $\begin{array}{l}\text { Desemp. } \\
\text { Amb }\end{array}$ & Sust. \\
\hline Felicidade & 1 & & & & & & & \\
Competitividade & $0,69^{*}$ & 1 & & & & & & \\
Inovação & $0,67^{*}$ & $0,97^{*}$ & 1 & & & & \\
TIC & $0,68^{*}$ & $0,96^{*}$ & $0,96^{*}$ & 1 & & & \\
Qualidade de Vida & $0,73^{*}$ & $0,79^{*}$ & $0,79^{*}$ & $0,81^{*}$ & 1 & & \\
DE & $0,62^{*}$ & & $0,88^{*}$ & $0,88^{*}$ & $0,86^{*}$ & 1 & & \\
DA & $0,59^{*}$ & $0,67^{*}$ & $0,59^{*}$ & $0,65^{*}$ & $0,68^{*}$ & $0,58^{*}$ & 1 & \\
Sustentabilidade & $0,26^{*}$ & $0,18^{* *}$ & $0,19^{* *}$ & $0,28^{*}$ & $0,43^{*}$ & $0,36^{*}$ & $0,46^{*}$ & 1 \\
\hline
\end{tabular}

Fonte: Carvalho (2010).

* - significante a $1 \%$; * - significante a 5\%;

A tabela 2 apresenta o número de países usados em cada uma dessas correlações.

Tabela 2 - Número de países usados nas correlações entre as variáveis

\begin{tabular}{l|l|l|l|l|l|l|l|l}
\hline & & & & & & $\begin{array}{l}\text { Desenv. } \\
\text { Econ. }\end{array}$ & $\begin{array}{l}\text { Desenv. } \\
\text { Amb. }\end{array}$ & Sust. \\
\hline Felicidade & Fel & Comp & Inov & TIC & QV & & & \\
Competitividade & 1 & & & & & & & \\
Inovação & 121 & 1 & & & & & \\
TIC & 118 & 128 & 1 & & & & \\
Qualidade de vida & 115 & 117 & 117 & 1 & & & \\
Desempenho Econômico & 102 & 99 & 99 & 97 & 1 & & \\
Desempenho Ambiental & 102 & 99 & 99 & 97 & 103 & 1 & & \\
Sustentabilidade & 130 & 115 & 113 & 110 & 99 & 99 & 1 & 1 \\
\hline
\end{tabular}

Fonte: Carvalho (2010).

A tabela 3 apresenta alguns resultados de pesquisas anteriores, comparados com os obtidos neste estudo. Comparando-se os resultados encontrados por Carvalho (2010) e por outros autores anteriores, verifica-se que eles apresentam-se bastante semelhantes.

Tabela 3 - Comparação de resultados de algumas correlações com outros estudos

\begin{tabular}{l|l|l|l|}
\hline & & & Fonte do "outro" estudo \\
Relação estudada & Este estudo & Outro estudo & \\
\hline Competitividade X PIB per capita & 0,85 & 0,75 & $\begin{array}{l}\text { The 2008 Legato Prosperity Index } \\
\text { Report } \\
\text { The 2008 Legato Prosperity Index } \\
\text { Report } \\
\text { Felicidade X PIB per capita }\end{array}$ \\
Felicidade X PIB (PPP) per capita & 0,62 & 0,76 & Deaton (2007) \\
Inovação X PIB (PPP) & 0,62 & 0,65 & Fagerberg e Srholec (2008) \\
Sustentabilidade* X Felicidade & 0,88 & 0,86 & Zidansek (2007) \\
Desempenho Ambiental X Felicidade & 0,26 & 0,35 & Zidansek (2007) \\
\hline
\end{tabular}

Fonte: Carvalho (2010). 
Ainda dentro das análises bivariadas, foram feitas regressões com a Felicidade para cada variável analisada, tendo sido testados quatro modelos: linear, quadrático, logarítmico cúbico. O primeiro e último modelos foram os que apresentaram os maiores coeficientes de determinação $\left(R^{2}\right)$ e muito semelhantes entre si, conforme pode ser visto na tabela 4. Novamente a Sustentabilidade foi a que apresentou menor coeficiente de determinação e a Qualidade de Vida o maior.

Tabela 4 - Coeficientes de determinação das regressões lineares e cúbicas

\begin{tabular}{llr}
\hline Variável Independente & $\mathrm{R}^{2}$ & $\mathrm{R}^{2}$ \\
\hline Qualidade de vida & Modelo Linear & Modelo Cúbico \\
Competitividade & 0,54 & 0,54 \\
TIC & 0,47 & 0,47 \\
Inovação & 0,47 & 0,47 \\
Desempenho Econômico & 0,45 & 0,46 \\
Desempenho Ambiental & 0,39 & 0,40 \\
Sustentabilidade & 0,35 & 0,38 \\
\hline
\end{tabular}

Fonte: Carvalho (2010).

\section{Análise do modelo proposto}

A análise do modelo proposto na figura 1 foi realizada por meio da utilização do método dos caminhos, que permite estudar as relações diretas e indiretas das variáveis em relação à Felicidade. Para a execução dessa análise, utilizou-se o software SmartPLS 2.0, que utiliza o método de estimação dos Mínimos Quadrados parciais.

A tabela 5 apresenta os resultados do teste de normalidade multivariada, realizada por meio do teste de Mardia, com o auxílio do software AMOS 5. Conforme observado, a amostra apresenta normalidade multivariada, na medida em que o valor do teste se mostrou abaixo do limite máximo de aceitação, igual a 3,00 (DIAS, 2004), tornando os resultados mais robustos.

Embora os dados tenham apresentado normalidade multivariada, optou-se pela utilização do método de mínimos quadrados parciais, mediante o tamanho reduzido da amostra disponível. Para a análise multivariada, a amostra foi reduzida para 92 países que estavam presentes em todas as oito variáveis (construtos) estudadas. Dessa maneira, a utilização do método de mínimos quadrados parciais tornou-se mais apropriada do que a utilização de outros métodos.

Tabela 5 - Teste de Normalidade Multivariada - Índice de Mardia

\begin{tabular}{lcccc}
\hline Variável & Assimetria & $\begin{array}{l}\text { Valor } \\
\text { crítico }\end{array}$ & Curtose & $\begin{array}{l}\text { Valor } \\
\text { crítico }\end{array}$ \\
\hline Sustentabilidade & $-0,422$ & $-1,652$ & 0,421 & 0,824 \\
DA & $-0,612$ & $-2,395$ & $-0,03$ & $-0,058$ \\
DE & 1,076 & 4,212 & 0,349 & 0,684 \\
Qualidade de Vida & 0,256 & 1,002 & $-0,719$ & $-1,407$ \\
Prontidão para TCl & 0,396 & 1,552 & $-0,724$ & $-1,417$ \\
Inovação & 0,511 & 2,003 & $-0,638$ & $-1,249$ \\
Competitividade & 0,447 & 1,75 & $-0,672$ & $-1,317$ \\
Felicidade & $-0,197$ & $-0,773$ & $-0,459$ & $-0,899$ \\
\hline Índice de Mardia & & & 7,214 & 2,735 \\
\hline
\end{tabular}

Fonte: Carvalho (2010).

Rev. Adm. UFSM, Santa Maria, v. 3, n. 2, p. 269-287, mai./ago. 2010 
A figura 2 apresenta os resultados empíricos obtidos por meio da visualização do diagrama de caminhos, sendo os valores junto às setas correspondentes aos coeficientes de caminho (beta), e os valores junto às elipses correspondentes aos coeficientes de determinação $\left(R^{2}\right)$.

No modelo proposto, observa-se que, diferentemente das análises realizadas anteriormente, quando todas as variáveis estavam diretamente relacionadas à Felicidade, apenas duas delas estão agora presentes: Qualidade de Vida e Sustentabilidade; as demais estão a ela associadas via construtos de permeio.

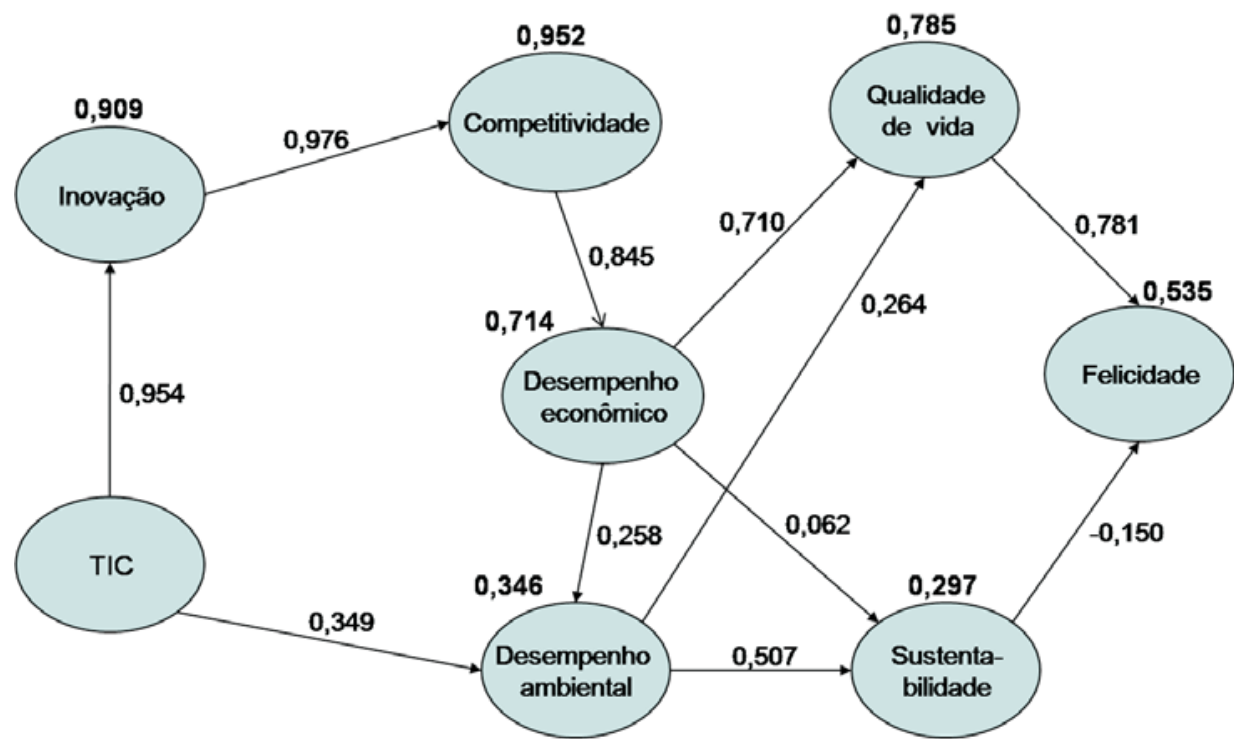

Figura 2 - Coeficientes de caminho (beta) e de determinação $\left(\mathrm{R}^{2}\right)$ obtidos para o modelo proposto.

Fonte: Carvalho (2010).

A tabela 6 apresenta aos coeficientes de caminho até a variável Felicidade, obtidos para cada construto em análise. Para a análise da significância dos coeficientes de caminho, utilizouse da técnica bootstrapping. Quanto aos coeficientes de caminho (Tabela 6), observa-se que a influência do Desempenho Econômico no Desempenho Ambiental (H5) e na Sustentabilidade (H6) não foi estatisticamente significativa, o que levou à rejeição dessas hipóteses de pesquisa.

Tabela 6 - Análise da significância das hipóteses

\begin{tabular}{llllll}
\hline Origem & Destino & Hipótese & $\begin{array}{l}\text { Coeficiente de } \\
\text { caminho }\end{array}$ & Teste t \\
\hline \multirow{2}{*}{ TIC } & Inovação & $\mathrm{H} 2$ & 0,954 & 103,7 & $*$ \\
& $\mathrm{DA}$ & $\mathrm{H} 3$ & 0,349 & 2,0 & $* *$ \\
\hline Inovação & Competitividade & $\mathrm{H} 4$ & 0,976 & 211,9 & $*$ \\
\hline Competitividade & $\mathrm{DE}$ & $\mathrm{H} 5$ & 0,845 & 24,5 & $*$ \\
\hline \multirow{2}{*}{ DE } & $\mathrm{DA}$ & $\mathrm{H} 6$ & 0,258 & 1,6 & \\
& Sustentabilidade & $\mathrm{H} 7$ & 0,062 & 0,7 & \\
\hline \multirow{2}{*}{ DA } & Qualidade de vida & $\mathrm{H} 8$ & 0,710 & 15,7 & $*$ \\
\hline Sustentabilidade & Sustentabilidade & $\mathrm{H} 9$ & 0,507 & 5,2 & $*$ \\
\hline Qualidade de Vida & Qualidade de Vida & $\mathrm{H} 10$ & 0,2635 & 4,4 & $*$ \\
\hline
\end{tabular}

Fonte: Carvalho (2010).

* - significante a $1 \%$; ** - significante a $5 \%$; 
A tabela 7 apresenta o efeito total de cada variável na Felicidade, bem como os resultados dos testes de significância, todas estatisticamente significativas sendo cinco delas a $1 \%$.

Tabela 7 - Efeito total de cada variável na Felicidade

\begin{tabular}{l|l|l|l}
\hline \multicolumn{1}{c|}{ Indicador } & Efeito total & Teste t & Significância \\
\hline Qualidade de Vida & 0,781 & 15,475 & Significativo a 1\% \\
Desempenho Econômico & 0,579 & 12,360 & Significativo a 1\% \\
TIC & 0,501 & 10,149 & Significativo a 1\% \\
Competitividade & 0,490 & 9,937 & Significativo a 1\% \\
Inovação & 0,478 & 9,726 & Significativo a 1\% \\
Desempenho Ambiental & 0,130 & 2,172 & Significativo a 5\% \\
Sustentabilidade & 0,150 & 2,068 & Significativo a 5\% \\
\hline
\end{tabular}

Fonte: Carvalho (2010)

Com vistas a validar o modelo, procedeu-se uma análise do coeficiente de determinação $\left(R^{2}\right)$, com base nos estudos de Cohen (1977). Segundo esse autor, o estado de desenvolvimento de grande parte da ciência do comportamento é tal que não muito da variância na variável dependente é previsível. Nesse sentido, o autor propõe uma escala para a classificação do coeficiente de determinação, sendo $\mathrm{R}^{2}$ igual a $10 \%$ considerado baixo, $\mathrm{R}^{2}$ igual a $30 \%$ considerado médio e $\mathrm{R}^{2}$ igual a 50\% considerado alto. Os resultados são expostos na TAB. 8.

Tabela 8 - Análise dos coeficientes de determinação $\left(R^{2}\right)$

\begin{tabular}{l|l|l|l|l|l}
\hline & $\begin{array}{l}\text { Baixo } \\
(10)\end{array}$ & $\begin{array}{l}\text { Médio } \\
(30)\end{array}$ & $\begin{array}{l}\text { Alto } \\
(50)\end{array}$ & $\begin{array}{l}\text { Muito } \\
\text { alto } \\
(70)\end{array}$ & $\begin{array}{l}\text { Extrem. } \\
\text { Elev. } \\
(90)\end{array}$ \\
\hline $\begin{array}{l}\text { Competitividade } \\
\text { Inovação }\end{array}$ & & & & & 0,95 \\
Qualidade de Vida & & 0,91 \\
$\begin{array}{l}\text { Desempenho Econômico } \\
\text { Felicidade }\end{array}$ & & 0,78 & 0,71 & \\
$\begin{array}{l}\text { Desempenho Ambiental } \\
\text { Sustentabilidade }\end{array}$ & & 0,39 & & & \\
\hline
\end{tabular}

Fonte: Carvalho (2010)

Nesta pesquisa, não foram observados valores inferiores a 10\% (baixos), sendo o menor valor igual a 30\% (médio) - para a variável Sustentabilidade - o que torna as relações estabelecidas aceitáveis. Ademais, cabe destacar que o coeficiente de determinação da variável Felicidade foi de 53,46\%, valor este considerado alto e que torna robusta a análise. Destaca-se também a existência de valores muito elevados para o coeficiente de determinação, como é o caso das variáveis Competitividade e Inovação, cujos valores são, respectivamente, 95\% e 91\%. 


\section{Conclusões}

\section{Uma síntese}

A análise das correlações mostrou que as variáveis (construtos) estudadas, sem exceção, apresentam relações positivas e significativas (a 1\%) com a Felicidade, entre estas a Competitividade e o Desempenho Econômico com coeficientes de Pearson respectivamente iguais a 0,69 e 0,62. Nessas correlações, a Qualidade de Vida foi o construto que apresentou maior intensidade (coeficiente de Pearson), enquanto a Sustentabilidade apresentou a menor.

Explorando ainda os dados disponíveis, correlações de todos os outros 21 pares possíveis de relações entre os outros construtos, que não com a Felicidade, revelaram coeficientes de Pearson altos e significativos. Além disso, os resultados do conjunto de correlações simples, envolvendo construtos que não a Felicidade, apresentam elevada concordância com estudos anteriores de outros autores.

$\mathrm{Na}$ análise das regressões simples, os coeficientes obtidos $\left(\mathrm{R}^{2}\right)$ confirmaram relação positiva e significativa de cada um deles com a Felicidade, muitas delas bastante intensas. Aqui, logo abaixo da Qualidade de Vida $\left(R^{2}=0,54\right)$, a Competitividade $\left(R^{2}=0,47\right)$, a Inovação $\left(R^{2}=\right.$ $0,45)$ e o Desempenho Econômico $\left(R^{2}=0,39\right)$ apresentaram de médio a elevado poder de explicação, considerando-se os critérios de Cohen para ciências sociais. Contudo, interessante notar que Inovação e Competitividade explicam melhor a Felicidade que o Desempenho Econômico. Regressão linear múltipla pelo método Stepwise mostrou apenas a variável Qualidade de Vida como significativa na explicação da Felicidade. Esse resultado, uma vez mais, demonstra que Qualidade de Vida - em que Desempenho Econômico (representado pelo PIB PPP per capita) participa apenas com $11 \%$ do total de pontos - é muito mais importante que a própria renda, para explicar a Felicidade. Daí pode ser percebido o equívoco estratégico que pode ocorrer se os administradores focarem o Desempenho Econômico como variável proxy de Qualidade de Vida ou, mais crítico ainda, como proxy da Felicidade.

Quanto à cadeia de relacionamento proposta até a Felicidade, a análise dos onze pares de relações apresentados no modelo revelou que a variância em nove delas é explicada de modo significativo a 1 ou a 5\%, o que resultou na aceitação das respectivas hipóteses. Nas hipóteses significativas, as seguintes relações foram positivas e de alta intensidade: a influência da Prontidão e Uso de TIC na Inovação; a influência da Inovação na Competitividade; a influência da Competitividade no Desempenho Econômico; a influência do Desempenho Econômico na Qualidade de Vida; a influência da Qualidade de Vida na Felicidade.

Tendo em vista que muitos construtos, no modelo, não apresentavam relação direta com a Felicidade, foi possível calcular o efeito total desses nesta última pelo método dos caminhos (Path Analisys), tendo sido encontrados como significativos a 1\%, exceto Desempenho Ambiental e Sustentabilidade, que o foram a 5\%.

Embora a análise das relações diretas propostas no modelo tenha encontrado duas hipóteses não aceitas, a validação do modelo deve se basear principalmente nos coeficientes de determinação, obtidos nas regressões de cada construto com as variáveis que levam a cada um deles. Aqui, todos os coeficientes de determinação se mostraram significativos a $1 \%$ quanto à intensidade da explicação. O uso de Tecnologia de Informação e Comunicação e a criação de ambiente favorável para seu desenvolvimento em um país explicam de modo extraordinariamente elevado a Inovação deste, do mesmo modo que esta última explica, também de modo extremamente elevado, a Competitividade, sempre do mesmo país. Seguindo o modelo, o 
Desempenho Econômico é fortemente determinado pela Competitividade; esta, principalmente junto com o Desempenho Ambiental, explicam muito bem a Qualidade de Vida. Por fim, a Felicidade tem, na Qualidade de Vida, um importante antecedente capaz de sozinha explicar $61 \%$ da variância da Felicidade. Não é de se surpreender com a força da Qualidade de Vida na explicação da Felicidade, pois, no índice agregado selecionado para representá-la, há um número significativo de aspectos que a literatura considera relevantes para o bem-estar. Os resultados obtidos com as análises estatísticas, usando o modelo proposto de interrelacionamento, indicam que há coerência na estratégia de investir na criação de ambiente favorável: para Uso de Tecnologia de Informação e Comunicação, para Inovação e para Competitividade do país, pois estas levam ao Desenvolvimento Econômico, que contribui também para a Qualidade de Vida, muito importante para explicar a Felicidade. Esta última é o único conceito que não é representado por um índice agregado no modelo proposto, mas apenas uma resposta simples, de cada pessoa, sobre como o nível de satisfação com a sua vida.

\section{Implicações gerenciais e acadêmicas}

Sendo a maior finalidade do poder público criar condições para melhorar o bem-estar subjetivo (a Felicidade média) da população, parece lógico que as diretrizes de nível mais elevado a tenha como referência. Saber o que faz as pessoas se sentirem felizes e desenvolver ações neste sentido seriam as mais nobres estratégias de governo. Os resultados confirmam também a limitação da renda/Desempenho Econômico para alcançar a Felicidade e a relevância de um amplo conjunto de aspectos contidos no conceito de Qualidade de Vida para esta última. A renda tem sua relevância, como demonstrado neste estudo, e em outros trabalhos, contudo ela deve ser entendida como um meio para viabilizar outros fatores que viabilizam o bem-estar subjetivo (felicidade), que tem, na Qualidade de Vida, um importante antecedente. Bem entendido que alguns governantes já estão caminhando neste sentido, como exemplo o conceito de Felicidade Interna Bruta em alguns países pioneiros, mas essa abordagem parece ser percebida ainda pela maioria dos que detêm o poder público como um modo ingênuo e muito abstrato de governo.

Nas organizações empresariais e nas demais organizações, interessa ter pessoas mais felizes porque elas são mais produtivas (OSWALD; PROTO; SGROI, 2009), mais criativas (CSIKSZENTMIHALYI, 1997; AMABILE, 2005) e mais fáceis de lidar (GIACOMONI, 2004). Por essa razão, programas relacionados à satisfação no Trabalho e também que possam impactar de modo positivo em outros domínios da vida podem e devem ser planejados e implementados. Mesmo reconhecendo a limitação da atuação da empresa na vida pessoal de seus empregados, ainda assim, com criatividade, eles podem ser planejados e implementados, como exemplo, entre outros, o horário flexível que, quando possível, contribui positivamente para a satisfação em outros domínios da vida.

O resultado do trabalho mostra que a Qualidade de Vida, sozinha, explica 61\% da Felicidade; na primeira, está incluída a renda per capita, porém, sua importância relativa no índice desse construto, é de apenas 11,5\%; os demais componentes são: saúde, segurança e estabilidade política, qualidade de vida familiar, qualidade de vida comunitária, clima e geografia, segurança de emprego, liberdade política e igualdade entre gêneros. Portanto, renda está contida na Qualidade de Vida, contudo, sua relevância como predecessor desses será maior à medida que não apareça dessa forma direta, mas sim indireta, ao ser eficazmente convertida em segurança pública, em educação e na saúde da população, entre outros serviços que a demandam. Deve ser lembrado também que a Qualidade de Vida pode melhorar por soluções 
criativas, muito pouco dependentes da renda, como, por exemplo, a saúde. Neste índice de Qualidade de Vida do IEU, é medida pela expectativa de vida após o nascimento, portanto, muito afetada pela mortalidade infantil, que foi reduzida drasticamente no Brasil por um programa que demanda muito pouca renda (Pastoral da Criança), demonstrando como a importância da renda pode ser reduzida.

Apesar da relevância da explicação encontrada (61\%) para a Felicidade, via Qualidade de Vida, está claro que o conjunto dos aspectos não incluídos no modelo é também relevante para explicá-la. Aos administradores fica o desafio de planejar e implementar programas de governo para atender os aspectos contidos na Qualidade de Vida, medidos de modo objetivo. À administração pública interessa também melhorar a explicação da Felicidade, identificando quais são os aspectos ainda não considerados no índice agregado de Qualidade de Vida, para que os programas de governo sejam cada vez mais eficazes em propiciar condições que favoreçam o bem-estar das respectivas populações. Aqui é provável que características regionais, tais como a cultura e a importância relativa das relações familiares e sociais, sejam uma limitação para a obtenção de uma única fórmula aplicável a qualquer região do mundo.

A análise do modelo proposto confirma que estratégias de governo que promovam a criação de ambiente favorável ao Uso da Tecnologia de Informação e Comunicação, a Inovação e a Competitividade nacional são positivas para o Desempenho Econômico, a Qualidade de Vida e a Felicidade.

\section{Limitações da pesquisa e oportunidade para futuras pesquisas}

Os resultados do trabalho mostraram que a Qualidade de Vida, usando o índice agregado selecionado no estudo, explica muito bem a Felicidade (ou seja, 61\% da sua variância), contudo restam ainda 39\% a explicar. À administração pública interessa melhorar a explicação da Felicidade, identificando quais os aspectos não ainda considerados no índice agregado de Qualidade de Vida, de modo a melhor orientar-se na definição de sua estratégia de governo, de modo a propiciar condições que maximizem o bem-estar das respectivas populações. Aqui é provável que características regionais, tais como a cultura e a importância relativa das relações familiares e sociais, sejam uma limitação para a obtenção de uma única fórmula aplicável a qualquer região do mundo, contudo esta busca de melhor explicação da Felicidade, mesmo que limitada a uma região geográfica menor, é uma oportunidade para novas pesquisas.

O poder de explicação do modelo pode ser aumentado por meio de outro desenho, incluindo a inclusão de outros conceitos não considerados aqui ou por meio de abordagem por clusters, esta última que pode viabilizar a captação de componentes culturais típicos de uma determinada região (ex: tendo em vista a menor renda, seria esperado menor nível de Felicidade em países da América do Sul e Caribe, o que não ocorreu, isso seria explicado pela teoria da influência da cultura, uma vez que, nessa região, as relações familiares e de vida em comunidade são mais valorizadas de modo que compensam a menor renda).

Além disso, análise de sensibilidade dos resultados às diferentes formas de compor a amostra (ex: diferentes níveis de riqueza de países) pode ser realizada. Do mesmo modo, experimentos com uso de outros índices relacionados a um mesmo construto podem ser realizados, embora Carvalho (2010) tenha analisado tal possibilidade e considerado pequena a chance de, em função disso, chegar-se a resultados significativamente diferentes.

Por último, há a questão temporal, pois mesmo que tenha havido cuidado em usar dados de surveys realizadas no mesmo ano, isso foi impossível devido a que elas possuem periodicidades diferentes. Carvalho (2010) indicou que o erro introduzido na pesquisa devido 
a este fato é aceitável devido aos coeficientes obtidos (da ordem de 0,96) para correlações de resultados de estudos anuais sucessivos, do mesmo modo que Easterlin (1974) e Oswald (1997) mostraram que os níveis de Felicidade variam muito pouco em uma mesma nação, mesmo considerando longos períodos. Fica, contudo, a possibilidade de uma tentativa, em futuras pesquisas, em ter tais dados mais alinhados no tempo.

\section{Referências}

AMABILE, T.M. et al. Affect and creativity at work. Administrative Science Quaterly, v. 50, n. 3, p. 367403, 2005.

ARISTÓTELES. Ética a Nicômaco. Bauru: Edipro, 2002.

BENTHAM, J. Uma introdução aos princípios da moral e da legislação. Tradução de Baraúna L. J. São Paulo: Abril Cultural, 1979.

BRADBURN, N.M. The structure of psychological well-being. Chicago: Aldine, 1969.

BRICH, F. Ética utilitarista de Jeremy Betham. Âmbito Jurídico, ano IX, nov. 2005

BRICKMAN, P.; CAMPBELL D.T. Hedonic relativism and planning the good society. In: APPLEY, M.H. (Ed.). Adaptation level theory: a symposium. New York: Academic, 1971. p. 287-302.

CANTWELL, J., (2002) Innovation and competitiveness In: FAGERBERG, J; MOVERY, D.C.; NELSON, R.R. (Ed.). Handbook of innovation. Oxford: Oxford Univ. Press, 2002. Chapter 21.

CARVALHO, M.B. A felicidade na agenda da administração: suas relações com conceitos organizacionais. 2010. Dissertação (Mestrado em Administração)Faculdade de Ciências Empresariais, Belo Horizonte, 2010.

COHEN, J. Statistical power analysis for the behavioral sciences. New York: Academic Press, 1977.

CONSTANZA et al. An integrative approach to quality of life measurement: research and policy. S.A.P.I.E.N.S 1 (1).2008. Disponível em: <http:// sapiens.revues.org/index169.html>. Acesso em: 05 set. 2009.
CSIKSZENTMIHALYI, M. Happiness and creativity: going with the flow. The Futurist, Washington, v. 31, 1997.

DAVEMPORT, T. H.; PRUSAK, L. Conhecimento empresarial. Rio de Janeiro: Campus, 1998.

DEATON, A. Income, aging, health and wellbeing around the world: evidences of the gallup world poll. 2007. Site da Princeton University. August. Disponível em: <http://princeton.academia.edu/ AngusSDeaton/Papers/26224>. Acesso em: 12 set. 2009.

DIAS, A. T. Competição, orientação estratégica e desempenho de empresas em ambiente turbulento: uma abordagem empírica. Dissertação (Mestrado em Administração)-Universidade Federal de Minas Gerais, Belo Horizonte, 2004.

DIENER, E.; LUCAS, R.E. Subjective emotional wellbeing. In: LEWIS, M.; HAVILAND, J.M. (Org.). Handbook of emotions. New York: Guilford, 2000. p. 325-337.

DIENER, E.; OISHI, S. The nonobious social psychology of happiness. Psychological Inquiry, v. 16, n. 4, p. 162-167, 2005.

Drucker, P. Desafios gerenciais para o século XXI. São Paulo: Pioneira, 1999.

DUTTA, S.; Mia, I. (2009) The Global Information Technology Report 2008 - 2009. INSEAD e WEF.

EASTERLIN, R. A. Does economic growth improve the human lot? In: DAVID, P.A.; REDER, M.W. (Ed.). Honour of Moses Abramovitz: nations and households in economic growth: essays. New York: Academic Press, 1974. p. 89-125. 
FAEME. Faculdade Evangélica do Meio Norte. Coordenação do Curso de Licenciatura em Filosofia, São Luís, 2009.

FAGERBERG, J.; SRHOLEC, M. National innovation systems, capabilities and economies. Research Policy, v. 37, p. 1417-1435, 2008.

FERNANDES, J. P. T. Ética e cidadania: o desafio dos novos valores. In: Conferência sobre Cidadania. Universidade Sênior. 2005.

FURTADO, C. O. Mito do desenvolvimento. Rio de Janeiro: Paz e Terra, 1974.

GARELLI, S. Competitiveness of nations: the fundamentals. IMD World Competitiveness. 2006. IMD World Competitiveness Yearbook.

GIACOMONI, C. H. Bem-estar subjetivo: em busca da qualidade de vida. Temas em Psicologia, v. 12, n. 1, 2004.

GONÇALVES, S. M. G. Elementos básicos para a formulação de política pública de gestão do conhecimento para a administração pública federal brasileira. Dissertação (Mestrado)-Universidade Católica de Brasília, Brasília, 2006.

GOTTMAN, J.M. What predicts divorce? The relationship between marital processes and marital outcomes. Hillsdale, NJ: Lawrence Erlbaum, 1994.

HUME, D. Ensaios morais, políticos e literários. Tradução de Monteiro, J.P.G.; D'Oliveira, A.M. 2. ed. São Paulo: Abril Cultural, 1980. (coleção Os Pensadores).

INSEAD. The global innovation ranking and report 2008-2009. 2009.

KITAYAMA, S.; MARKUS, H.R. The pursuit of happiness and the realization of sympathy: Cultural patterns of self, social relations, and well-being. In: DIENER, E.; SUH, E. M. (Eds.). Culture and subjective wellbeing. Cambridge: MIT Press, 2000. p.113-164.

Krugmam, P. R. Competitiveness: a dangerous obsession. Foreign Affairs, v. 94, p. 28-44, 1994.
MACHLUP, F. Knowledge: its creation, distribution and economic significance. In: The Economic of Information and Human Capital. Princeton: Princeton University Press, 1984.

MEIRELLES, H.L. Direito administrativo brasileiro. 20. ed. Sao Paulo: Malheiros, 1995.

MITELKA, L. K. Local system of innovation in a globalized world economy. Industry and Innovation, v. 7, n. 1, p. 15-32, 2000.

OSWALD, J. A. Happiness and economic performance. The Economic Journal, Oxford, Royal Academy Society, v. 107, p. 1815-1831, 1997.

OSWALD, J. A.; PROTO, E.; SGROI, D. Happiness and productivity. Dept of Economics, University of Warwick, Coventry, UK. March. Disponível em: <http://www.york.ac.uk/depts/econ/documents/ seminarpapers/oswald_paper_0609.pdf>. Acesso em: 20 set. 2009.

PORTER, M. A vantagem competitiva das nações. In: SERRA, A.C. S. Competição: estratégias competitivas essenciais. Rio de Janeiro: Campus, 1999. p. 167-208.

SALA-I; MARTI, X. The global competitiveness report 2009-2010. In: SCHWAB, K. (Ed.). World Economic Forum, 2009.

SANTOS, A.R. et al. Gestão do conhecimento como modelo empresarial. In: Gestão do Conhecimento. Brasília: SERPRO, 2001.

SCIENCE DAILY. Psychologist produces the first-ever "World Map of Happiness". 14 nov. 2006.

SEAGER, A; STEWART, H. Economists starts to consider that money can't buy happiness. Disponível em : <http://www.guardian.co.uk/business/ 2010/jan/10/economic-growth-feel-good-factor $>$. Acesso em: 15 jan. 2010.

SHUMPETER, J.A. The theory of economic development. 10. ed. New Brunswick: Transactions, 1983. 
SSF. Sustainable Society Foundation. Disponível em: $<$ http://www.sustainablesocietyindex.com/ssidescription.htm >. Acesso em: 29 nov. 2008.

THOMPSON, E. R. A grounded approach to identifying national competitive advantage: a preliminary exploration. Environment and Planning, v. 35, p. 631- 657, 2002.

TYSON, L.D.A. Who's bashing whom: trade conflict in high technology industries. Washington DC: Institute for International Economics, 1992.

UNITED NATIONS. World commission on environment and development: towards sustainable development. 1987. In: BRUNTLAND, Gro H. et al. Our common future. Disponível em: <http:// www.un-documents.net/wced-ocf.htm $>$. Acesso em: 15 ago. 2009.

VEENHOVEN, R. Measures of gross national happiness. In: OECD World Economic Forum on Statistics - Roundtable on "Measuring, Knowledge and Policy. Istanbul: June 2007.

VEENHOVEN, R. How universal is happiness? Presented at Conference of International Differences in Well-Being. Princeton University, 2008.

VEENHOVEN, R. World database of happiness. Erasmus University Rotterdam. Disponível em: $<$ http://worlddatabaseofhappiness.eur.nl $>$. Acesso em: 16 jul. 2009.

ZIDANSEK, A. Sustainable development and happiness in nations. Energy, v. 32, p. 891-897, 2007. 